\title{
WHAT IS THE BEST CARE FOR COMMUNITY-DWELLING DEPENDENT ADULTS? \\ Sources of care and perception of unmet needs in Spain
}

\author{
¿CUÁL ES EL MEJOR CUIDADO PARA LOS ADULTOS DEPENDIENTES \\ NO INSTITUCIONALIZADOS?
}

Fuentes de cuidado y percepción de necesidades no satisfechas en España

\author{
Jesús Rogero-García jesus.rogero@uam.es \\ Universidad Autónoma de Madrid. Spain.
}

Karim Ahmed-Mohamed karim.ahmed@cchs.csic.es

Centro de Ciencias Humanas y Sociales (CCHS-CSIC). Spain.

\begin{abstract}
The objectives of this study in the Spanish context are: (1) to identify what source of care (informal, private or public care) achieves the lowest perception of unmet needs amongst dependent adults and (2) to identify which factors are associated with a greater perception of unmet needs within each source of care. This research is based on a sample of 4,766 dependent adults who completed the 2008 Survey on Disability, Personal Autonomy and Dependency Situations (EDAD). Dependent adults who received only paid care were less likely to perceive unmet needs compared to those who received other types of care. Dependents who received public care were more likely to perceive unmet needs. Perception of unmet needs is related to the characteristics of the dependent adults, the primary carers and the caregiving context. The results suggest that policy design must not assume that dependent people prefer family care to other types of care and demonstrate that public care is perceived as unsatisfactory.
\end{abstract}

\section{KEYWORDS}

Care services; Disabled people; Informal care; Paid care; Social support.

\section{RESUMEN}

Los objetivos de este trabajo son: (1) identificar el proveedor de cuidado (informal, privado o público) que consigue una menor percepción de necesidades no cubiertas entre los adultos dependientes en España, (2) identificar qué factores se relacionan con una mayor percepción de necesidades no cubiertas en cada situación, atendiendo al proveedor de cuidado. Se analizó una muestra de 4.766 adultos dependientes de la Encuesta sobre Discapacidades, Autonomía personal y situaciones de Dependencia (EDAD 2008). Los adultos dependientes que recibieron únicamente cuidado privado tuvieron menos probabilidades de percibir sus necesidades no cubiertas, en comparación con quienes recibieron cualquier otro tipo de cuidado. Quienes recibieron cuidado solo de servicios sociales tuvieron más probabilidades de percibir sus necesidades como no cubiertas. La percepción de necesidades no cubiertas está relacionada con las características de la persona dependiente, del cuidador y del contexto del cuidado. Los resultados sugieren que el diseño de políticas públicas no debe dar por supuesto que las personas dependientes prefieren el cuidado familiar por encima de otras fórmulas de atención y muestran que los servicios públicos de cuidado son percibidos como insatisfactorios.

\section{Palabras clave}

Apoyo social; Cuidado informal; Cuidado pagado; Personas con discapacidad; Servicios de cuidado. 


\section{INTRODUCTION}

In spite of the difficulties associated with its implementation in Spain (Escuredo 2007), Spanish Law 39/2006 has been an important milestone in establishing rights and providing benefits and services to improve dependent people's quality of life (Carretero et al. 2009). Nevertheless, the recent economic crisis has limited the advances originally planned by the 39/2006 Law. This lack of resources is likely increasing unmet care needs among dependent Spanish adults and reducing their quality of life. These negative consequences are experienced not only by those who state that they need help and are not given any at all, but also by those who do not receive enough help (Allen and Mor 1997). The consequences that have been identified include an increase in depression (Lai 2004; Otero et al. 2003), loss of autonomy (Harlton, Fast and Keating 1998), institutionalisation (Desai, Lentzner and Weeks 2001), and an intensification in health service use such as medical consultation and emergency services (Allen and Mor 1997). Therefore, studies on unmet needs can contribute to the discussion of social protection of dependent adults and provide crucial information for efficient policy development to improve their quality of life (Thorslund, Bergmark and Parker 1997), especially in the context of limited family and state resources (Daatland 1997).

One of the relevant aspects of the care received by dependent adults is related to what is the main source of care and what institutions are funding it (Crow et al. 2002). In this sense, assessing the influence of different sources of care on meeting the needs of dependent people has been recognised as a relevant but relatively scarcely explored topic (Vlachantoni et al. 2011). Many studies have analysed the distribution of care by care providers in Spain (e.g., Casado-Marín 2006; Larizgoitia Jaúregi 2004) and in other countries (e.g., in Europe: European Commission 2009; Mestheneos and Triantafillou 2005; Pommer, Woittiez and Stevens 2007). However, there are few studies examining the level of satisfaction regarding met needs in relationship to the different sources of care received by dependent adults. In Spain, four studies on unmet needs are worth mentioning. Otero et al. (2003) analysed unmet needs in activities of daily living (ADLs) and instrumental activities of daily living (IADLs) in a representative sample of people over 64 years of age in a municipality in the metropolitan area of Madrid (Leganés) in 1993. Tomás Aznar et al. (2002) used 1998 data of people over 74 years of age from a neighbourhood in Zaragoza to identify factors associated with unmet home care needs in different basic ADLs. In both studies, needs coverage was measured in terms of the frequency of help received for each activity in relation to the theoretical help needed. Jiménez-Martín and Vilaplana (2010) analysed informal carer responses towards their older care receivers' unmet needs in a representative sample from Spain in 2004. None of these studies took into consideration the source of care received by dependent people. Lastly, Rogero-García and Ahmed-Mohamed (2011) used a national sample from 2008 composed of disabled people over the age of 59 to analyse their perception of unmet needs. This work included, for the first time, the source of care as an independent varia- 
ble, but it did not study the effect of the different sources of care separately and did not include people from 18 to 59 years of age.

This study tries to resolve the above-mentioned limitations. It focuses on the subjective perception of unmet needs of non-institutionalised dependent adults who receive any of the following sources of care - or a combination of any of these - in Spain: informal care (from the family or other acquaintances), paid care from private services (paid for entirely by the dependent person and/or his or her relatives) and care from public services (at least partly financed by public institutions). The objectives of this paper are: (1) to identify the source of care that achieves the lowest perception of unmet needs amongst dependent adults and (2) to identify which factors are associated with a greater perception of unmet needs within each source of care.

Unmet or unsatisfied needs appear when personal help is considered inadequate, insufficient or nonexistent (Isaacs and Neville 1976; McWalter et al. 1994; Quail et al. 2007; Williams, Lyons and Rowland 1997). A specific unmet need "is determined by the interaction between a person's type and level of need and the type and level of support they receive, and is affected by their demographic, socio-economic and health status characteristics" (Vlachantoni et al. 2011:6). Although the concept of need has been recognised as elusive (Lightfoot 1995), there is consensus on the fact that needs are personal, subjective and have different meanings according to the context in which they are used (Cowley et al. 2000; McWalter et al. 2004; Willard 1982). The relationship between care and needs is not clear, as needs depend on individual expectations and the context (Asadi-Lari, Tamburini and Gray 2004). For instance, difficulties with ADLs cannot be considered to be equivalent to the specific needs of dependents, given that the difficulties themselves do not explain which specific needs must be covered. Williams, Lyons and Rowland (1997) established four types of characteristics related to the perception of unmet needs: variables related to the dependent person, environmental variables, variables concerning the care received and variables of the primary carer.

The subjective perception of the care received is conditioned by contextual characteristics such as the public care services or the cultural norms and values about care responsibilities ( $\mathrm{Ng}$ 2007:39-41). Although international comparisons must be taken with caution, analyses from Spain may offer information about dependent adults living in countries with similar values and public social protection systems, as Spain is an appropriate example of a "Familist" country, where family plays a predominant role in care responsibilities (Esping-Andersen 1999; Anttonen and Sipilä 1996). In Spain, care of dependent adults continues to be based primarily on family care. It was estimated in 2007 that $79 \%$ of dependent Spanish people of all ages received care solely from their families, a statistic 20 points above the European average (27 countries) (European Commission 2009). It is also well known that women usually undertake care-related responsibilities: in Spain, $83 \%$ of the main family carers are women (IMSERSO 2005a). On the other hand, around $14 \%$ of dependent people (> 5 years) receive private paid care (Rogero-García 2011). Although this type of care is frequently intensive in terms of time, it is normally provided by unqualified workers with low salaries, who do not have a formal contract 
and, especially in urban areas, are immigrants (Rodríguez 2012; Pérez, Paiewonsky and García Domínguez 2008).

Public services provide care to $7 \%$ of dependent people over 5 years of age (RogeroGarcía 2011). According to official Spanish statistics (IMSERSO-CSIC 2012), of the total services and provisions from the public system allotted for dependent adult care, $13.5 \%$ corresponded to the telecare service (monitoring and intervention in view of situations that involve emergencies, lack of security, loneliness and isolation), 13.4\% corresponded to permanent residential care services, $12.9 \%$ to home help services (in ADLs, such as cleaning, cooking, shopping, etc.), $6.4 \%$ to the Day/Night Centre service (complete care during the day or night), and $1.9 \%$ were actions aimed at preventive services. The rest $(52 \%)$ consisted of direct economic benefits to families. Therefore, the public care services in the home generally consist of short periods of care aimed at helping with specific activities or at certain times of day.

All European countries are currently trying to redefine the division of care responsibilities among the family, private market and government (Bettio and Plantenga 2004). Although the family is still the primary care provider, there have been calls for support from the public and private care sector. Along these lines, formal and informal care have been described as containing distinct characteristics and playing varying roles (Lewinter 1999). Formal care has usually been associated with technical specialisation and informal care with inter-personal bonds (Donabedian 1988). However, this association should not be assumed due to the great diversity of care situations. For instance, it has been noted that many formal carers develop important emotional ties with dependent individuals and that relatives frequently develop adaptive care skills during the care process (Rodriguez 2012). In terms of the quality of care, some argue that the family provides better support than the state or the private market because informal care is assumed to involve not only the coverage of physical needs, but also emotional elements (Montgomery 1999). Additionally, previous studies in Spain (IOÉ and Rodríguez 1995; IMSERSO 2005) have shown that when people are asked who they would prefer to be cared by in the event of becoming dependent, the great majority choose family members. In light of this, our hypotheses are the following:

- $\quad \mathrm{H} 1$ : The source of care is one of the key variables influencing the perception of unmet needs.

- H2: People being cared for solely by their family would have the lowest perception of unmet needs.

- H3: People who receive care only from the state would have the highest perception of unmet needs.

- H4: Care provided by paid and unrelated carers would receive an intermediate position.

The effect of care on needs satisfaction can be measured by (1) assessing the relationship between the different types of care (e.g., tasks to help with ADLs performance) 
and the degree to which those needs are met by each specific type of care or (2) a subjective indicator that captures the overall satisfaction with the care received. In the first case, different needs must be predefined by the researcher and must be causally linked to individual care tasks. For instance, the studies in Spain by Tomás Aznar et al. (2002) and Otero et al. (2003) analysed the care needs for different ADLs, which were considered unmet when the help required to carry out these daily activities was not received. These types of indicators are often used when the needs analysis is individual and is connected to the provision of services (Cowley et al. 2000; McWalter et al. 1994). However, the indicators compounded by different specific needs can fail to include all of the dependent adults' relevant needs. They can also fail to adequately link care tasks and needs. In these cases, the needs are often defined in relation to the respondent's information about available formal care services (McWalter et al. 1994), thus obscuring a large number of the population's actual needs (Asadi-Lari, Tamburini and Gray 2004).

Another common way of measuring dependents' satisfaction with care services is through global measures that ask for their general opinion about the care received (Bauld, Chesterman and Judge 2000). In these cases, the measure of satisfaction is not linked to an individual need, but rather it is connected to an overall vision that is the result of a subjective assessment. The main weakness of global satisfaction measures is that they do not capture opinions of different aspects of care (material, communicative, emotional, etc.), and it is therefore not possible to know whether an individual is more satisfied with one aspect than with others (Bauld, Chesterman and Judge 2000). On the other hand, the global and subjective indicators make it possible to deal with the felt and expressed needs defined by Bradshaw (1974). Felt needs are equivalent to wants, and are based on people's own beliefs and expectations. Felt needs become expressed needs when they have been formulated as a demand. An overall expressed needs indicator measures the population's needs from a sociological perspective and has been recognised as important for the planning of services (McWalter et al. 1994; Billings and Cowley 1995; Vlachantoni et al. 2011).

\section{Methods}

\section{Data source}

Information from the 2008 Survey on Disability, Personal Autonomy and Dependency Situations (EDAD) produced by Spain's National Statistics Institute (INE) was used. The main purpose of this survey is to provide a statistical basis for promoting personal autonomy and prevent dependency situations (INE 2008). This is the most recent survey containing detailed information on disability and dependency in Spain and its respective Autonomous Regions (Comunidades Autónomas). A total of 258,187 community-dwelling people were interviewed, of which 22,795 reported some type of disability. The large sample size and questionnaire of the EDAD Survey make it the most suitable source of information to assess unmet needs perception in relation to the different types of care received. 


\section{Sample}

The information from the survey was collected through face-to-face interviews, which were sometimes supplemented with telephone interviews. Of the total number of disabled individuals, only those over the age of 18 who responded directly to the question about the source of care they received were included in this study (4,766 dependent adults). Therefore, the analyses did not include non-dependent disabled individuals, dependents who did not inform about the source of care received, or dependents who informed that they did not receive any source of care. We only selected information provided personally by the dependents themselves, as the dependent variable is a subjective indicator. The information provided by indirect informants (proxies) is less reliable than the responses provided by the disabled person regarding the subjective aspects of their quality of life (Sprangers and Aaronson 1992; Todorov and Kirchner 2000). This greater degree of inaccuracy is due to the way the care affects proxies; normally the spouse or one of the children of the dependent person (Williams, Lyons and Rowland 1997). Specifically, dependent people are significantly more likely to express dissatisfaction with care than people who respond for them (Desai, Lentzner and Weeks 2001). The primary carer also provided personal information about themselves when filling out a specific section of the questionnaire.

\section{Measures}

The main dependent variable of this study was the response to the following question: Do you believe the help you receive from other people satisfies your needs? Yes/no, it is insufficient. The answer to this question is an adequate measure of the general care situation of the dependent person from the felt and expressed needs perspective (Bradshaw 1974).

Dependent adults identified each of the people who provided them with care in and outside of their homes, as well as the people employed in their house or financed by the public administration. For this study, the source of care received variable was made up of six categories: receiving only informal care (family or friends); receiving only private or paid care (provided by a paid carer fully funded by the dependent person or his/her family); receiving only public care (at least in part publicly funded); receiving informal care and paid care; receiving informal care and public care; and receiving a combination of care from the three sources. Apart from the source of care, four other independent variables were also chosen according to the Williams, Lyons and Rowland (1997) classification (categories reflected in Table 2):

a) Variables concerning the dependent person: gender, age, number of disabilities (from a list of 44 problems encountered in performing ADLs) and level of education. 
b) Environmental variables: the size of household (number of people living together in the household), monthly household income and the size of the municipality (number of inhabitants).

c) Variables regarding the care received: carer's place of residence and hours of care received (estimated by the dependent person).

d) Variables concerning the primary carer (the person who performs the majority of the care tasks): gender, relationship, employment status, level of education, years the carer has been providing care to the care receiver, nationality and care-related problems (difficulties with the care itself, health problems, work problems and problems with social or leisure relationships).

\section{Analysis}

Bivariate contingency tables were used to explore basic relationships between explanatory variables and perception of unmet needs for people receiving care by any of the sources, only by informal carers, only by paid carers and only by social services. Differences between groups were analysed with the Chi-square test. Various binary logistic regression models were also used to identify factors associated with perceived unmet needs for people receiving any source of care and for each of them. These models predict the probability of an event occurring under certain circumstances (Harrel 2001).

The general model of the perception of unmet needs for people receiving any of the sources of care used independent variables concerning the dependent person (a), the environment (b), hours of care, and source of care received. The model of the perception of unmet needs of people receiving only care from informal carers included the four types of independent variables. The model of the perception of unmet needs of people receiving only paid care included (a), (b) and (c) as independent variables, as well as some of the carer's characteristics (nationality and level of education). The model of the perception of unmet needs of people receiving only care from social services included (a), (b) and hours of care received as independent variables. Some of the variables concerning the care received and of the carer's characteristics were not included in the first and the last two models due to the high number of missing cases amongst those who received paid care and because they were not collected for social service carers.

Some categories of explanatory variables were grouped together to obtain a sufficient number of cases to comply with the robustness criteria in the logistic regression models as established by Hosmer and Lemeshow (1989). The enter method was used to include variables in the regression models. Pearson's Chi-square and Nagelkerke's $R^{2}$ test were used to measure the fit of the models (Norusis, 2005). $P<0.05$ was used as the significance level for all tests. Multicollinearity was tested with the tolerance factor; variables with a tolerance factor of less than 0.250 were excluded from the models. Data were analysed with SPSS software version 17. 


\section{Results}

Table 1 shows the percentage of dependent people that receive the different types of care identified and the percentage of people who believe that the care they receive does not satisfy their needs. The most common source of care is an informal carer, with $79 \%$ of people cared for exclusively by one or more family members or friends. Just over $10 \%$ also receive help from paid carers, social services or both. Of those who do not receive informal help, the remaining $10 \%$, the majority receive paid care. $29.4 \%$ of dependent people believe the care they receive does not cover their needs. Help provided exclusively by social services has the highest percentage of perceived unmet needs (47.2\%), while those who receive help exclusively from privately paid carers have the highest frequency of perception of satisfied needs (22\%). People who receive care from more than one source have a higher percentage of perceived unmet needs than the rest, with this trend highest amongst those who receive care from a combination of all three sources (54.5\%). Of people receiving only informal care, $28.1 \%$ perceive unsatisfied needs.

A higher percentage of women perceive their needs to be unmet (32\% versus $25 \%$ of men) (Table 2). The same occurs with people who need help in more than 12 ADLs $(41 \%)$, dependent people with only primary school education or incomplete education $(30 \%)$, those living in municipalities with over 100,000 inhabitants $(33 \%)$ in households with one $(38 \%)$ or two members $(31 \%)$, and in households with a monthly income of under 500 euros (39\%). The trend continues with dependent people who have been receiving care for eight years or more $(30 \%)$, those whose primary carers do not live

Table 1.

Dependent adults (>17 years) who perceive unmet needs by source of care received. Spain 2008

\begin{tabular}{lrrc}
\hline & \multicolumn{2}{c}{$\begin{array}{c}\text { Perception of unmet } \\
\text { needs }(\%)\end{array}$} \\
\hline Informal care (from family or friends) & 3,801 & 78.5 & 28.1 \\
Public care & 151 & 3.6 & 47.2 \\
Paid care & 306 & 7.3 & 22.0 \\
Informal care and public care & 151 & 2.9 & 45.4 \\
Informal care and paid care & 335 & 7.1 & 34.8 \\
Informal care, paid care and public care & 22 & 0.5 & 54.5 \\
Total & 4,766 & 100.0 & 29.4 \\
\hline
\end{tabular}

${ }^{a} \mathrm{~N}$ are the unweighted number of observations. All percentages are calculated as weighted with sampling weights. Source: 2008 Spanish Survey on Disability, Personal Autonomy and Dependency Situations. 
with them $(36 \%)$, whose primary carer is male $(35.1 \%)$ and whose carer has care-related problems $(32 \%)$. These patterns also occur for people receiving care exclusively from informal carers. In this case, the dependent person's level of education is not significant, but the number of care hours he/she receives is: the higher the number of care hours, the higher the percentage of dependent people who say that their needs are not satisfied. As for people receiving care exclusively from paid carers, significant differences are noticed in level of education, the carer's place of residence, number of household members, and care hours given. For those being helped exclusively by social services, only level of disability and educational level show a level of significance below 0.05 .

Displayed below are the logistic regression models that help to identify the associations between the independent variables and perceived unmet needs. Table 3 shows the model for all of the sources of care. The odds that a dependent adult perceives his/her needs to be unmet are reduced by $36 \%$ if the individual only receives paid care compared to receiving only informal care. If the help is received exclusively from social services, the odds of not considering his/her needs as having been met are $70 \%$ higher than when only informal care is received and $65 \%$ higher if the care received is jointly provided by social services and informal care.

The probability of perceiving unmet needs is higher if the person who receives the help is a woman $(O R=1.424)$. When compared to people with six disabilities or fewer, the odds of perceiving unmet needs are increased by $272 \%$ for those with 12 or more disabilities. When compared to those between 65 and 79 and those over the age of 79 , the odds of perceiving their needs as having been met are reduced by $22 \%$ and $40 \%$, respectively, amongst people under the age of 65 . The probability of perceiving their needs as having been met is lower if the dependents live alone compared to those who live in homes with three or more people $(\mathrm{OR}=0.622)$. The odds of perceiving care needs as having been met are reduced by $28 \%$ for those who live in homes with an income of less than 500 euros per month, compared to those who live in homes with an income of more than 1,000 euros. The odds of perceiving needs as unmet are reduced by approximately 20\% amongst dependents who live in towns with fewer than 100,000 inhabitants.

Table 4 shows the model of factors related to unmet needs amongst those who only receive informal care. The primary carer having problems related to the care tasks increases the probability of perceiving insufficient coverage of the dependent adult's needs (OR $=2.561$ ). The odds of perceiving unmet needs among those who receive more than nine hours of care per day increase by $67 \%$ when compared to those who receive care only one to two hours per day. Those whose primary carer is a man are less likely to perceive their care needs as having been met than those whose primary carer is a woman (OR $=0.938$ ). When compared to people who live with their primary carer, the odds ratio of perceiving needs as unmet by those who do not live with their carer is increased by $65 \%$. The model also selected the following risk factors for the perception of insufficient needs coverage: being a woman, having a severe level of disability, living in homes with a monthly income of less than 500 euros, living in cities with more than 100,000 inhabitants, and having an informal carer who also works. 


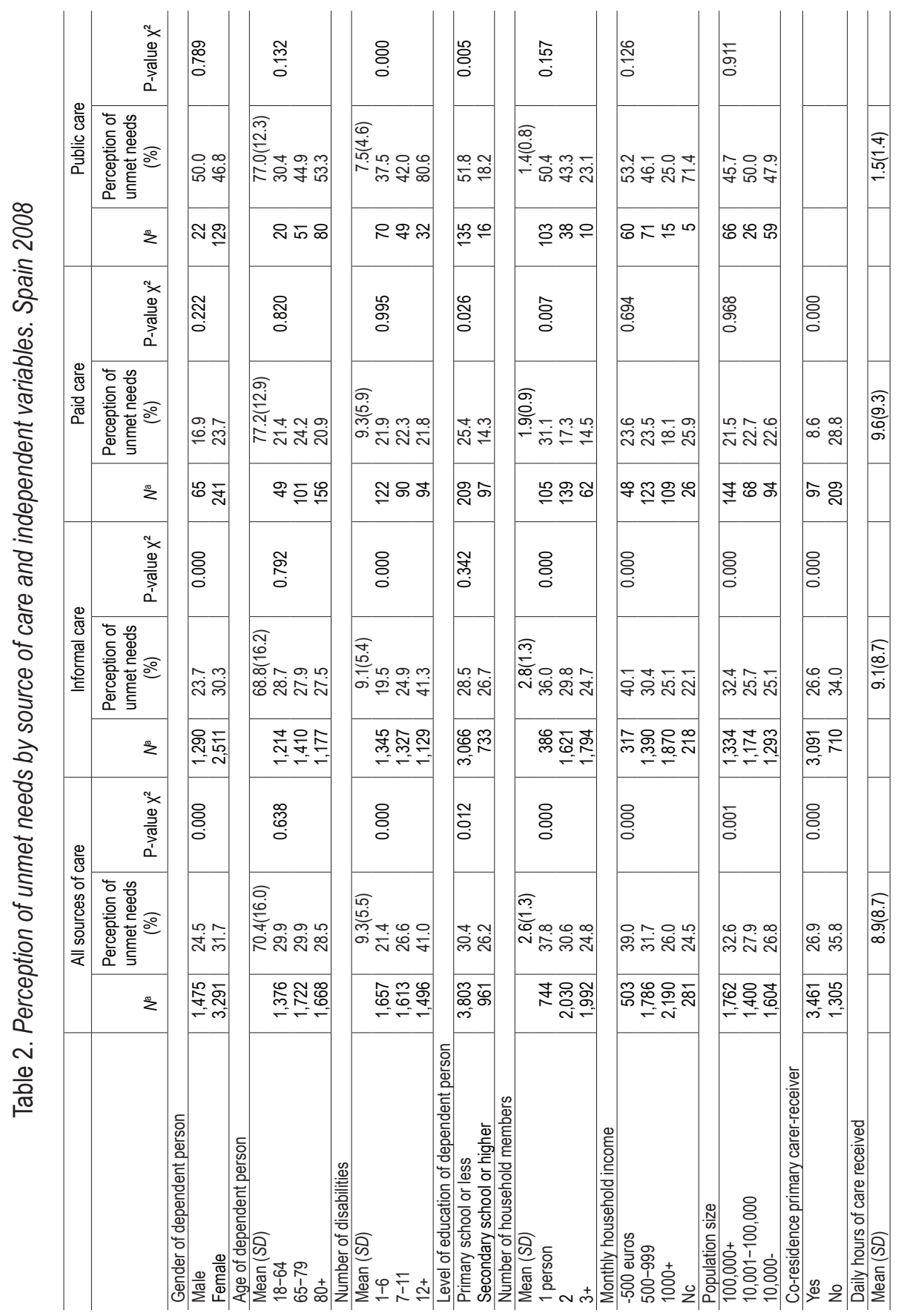




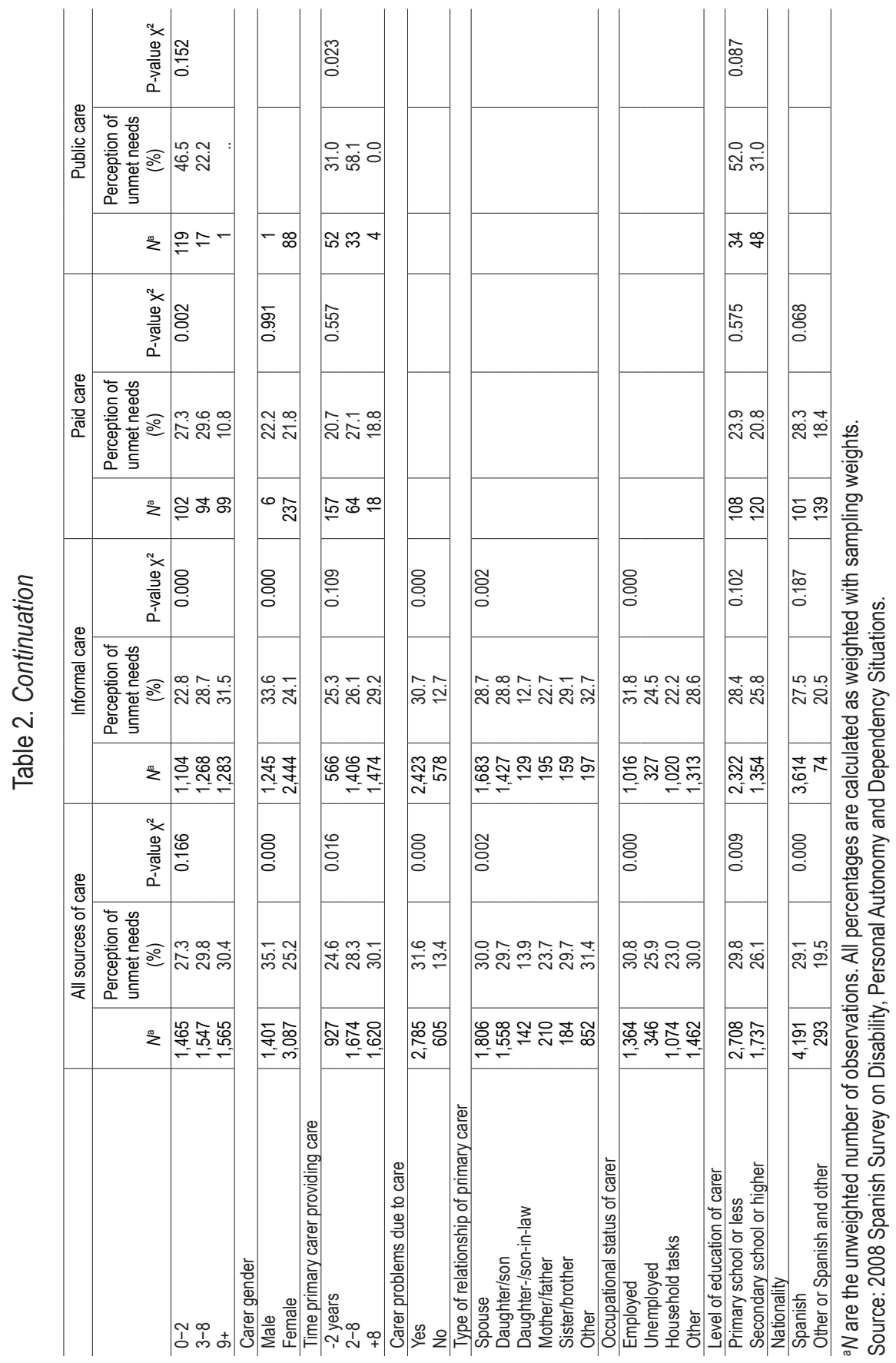


Table 3.

Logistic regression model of perception of unmet needs. All sources of care

\begin{tabular}{|c|c|c|}
\hline Perception of needs (ref: receive all care he/she needs) & P-value & OR \\
\hline Gender (ref: male) & 0.000 & 1.424 \\
\hline Number of disabilities (ref: 1-6) & 0.000 & \\
\hline $7-11$ & 0.001 & 1.367 \\
\hline $12+$ & 0.000 & 2.721 \\
\hline Dependent person's age (ref: 18-64) & 0.000 & \\
\hline $64-79$ & 0.009 & 0.779 \\
\hline $80+$ & 0.000 & 0.600 \\
\hline Level of education of dependent person (ref: primary school or less) & 0.052 & 0.830 \\
\hline Number of household members (ref: 1) & 0.000 & \\
\hline 2 & 0.098 & 0.826 \\
\hline $3+$ & 0.000 & 0.622 \\
\hline Monthly household income (ref: -500 euros) & 0.032 & \\
\hline 500-999 & 0.184 & 0.848 \\
\hline+1000 & 0.014 & 0.715 \\
\hline No answer & 0.016 & 0.624 \\
\hline Population size (ref: $100,000+$ ) & 0.003 & \\
\hline $10,001-100,000$ & 0.007 & 0.800 \\
\hline $10,000-$ & 0.003 & 0.767 \\
\hline Daily hours of care received (ref: 0-2) & 0.411 & \\
\hline 3-8 & 0.374 & 1.085 \\
\hline $9+$ & 0.760 & 0.971 \\
\hline Source of care (ref: informal care) & 0.000 & \\
\hline Public care & 0.005 & 1.706 \\
\hline Paid care & 0.003 & 0.644 \\
\hline Informal care and public care & 0.008 & 1.651 \\
\hline Informal care and paid care & 0.363 & 1.130 \\
\hline Informal care, paid care and public care & 0.022 & 3.074 \\
\hline Constant & 0.000 & 0.507 \\
\hline
\end{tabular}

$\mathrm{N}: 4.470$. Chi-square: $283.745 p<0.001$. Nagelkerke's $R^{2}: 0.092$.

Note 1: Different combinations of reference categories have been produced for "source of care". These categories showed: (1) less coverage of needs for "social services" compared to "informal care", "paid care" and "informal care and paid care"; (2) greater coverage of needs in "paid care" in relation to any other combination of care. Note 2: Multicollinearity tests: lowest tolerance factor $=0.638$; highest VIF $=1.567$.

Source: 2008 Spanish Survey on Disability, Personal Autonomy and Dependency Situations. 
Table 4.

Logistic regression model of perception of unmet needs. People receiving only informal care

\begin{tabular}{|c|c|c|}
\hline Perception of needs (ref: receive all care he/she needs) & P-value & OR \\
\hline Gender (ref: male) & 0.044 & 1.295 \\
\hline Number of disabilities (ref: 1-6) & 0.000 & \\
\hline 7-11 & 0.052 & 1.279 \\
\hline $12+$ & 0.000 & 2.284 \\
\hline Dependent person's age (ref: 18-64) & 0.116 & \\
\hline $64-79$ & 0.371 & 0.885 \\
\hline $80+$ & 0.044 & 0.729 \\
\hline Level of education of dependent person (ref: primary school or less) & 0.884 & 0.980 \\
\hline Number of household members (ref: 1) & 0.207 & \\
\hline 2 & 0.140 & 1.508 \\
\hline $3+$ & 0.336 & 1.335 \\
\hline Monthly household income (ref: -500 euros) & 0.003 & \\
\hline 500-999 & 0.067 & 0.687 \\
\hline+1000 & 0.001 & 0.504 \\
\hline No answer & 0.013 & 0.483 \\
\hline Population size (ref: $100,000+)$ & 0.000 & \\
\hline $10,001-100,000$ & 0.000 & 0.662 \\
\hline 10,000 & 0.003 & 0.701 \\
\hline Primary carer gender (ref: male) & 0.020 & 0.938 \\
\hline Relationship (ref: daughter/son) & 0.430 & \\
\hline Spouse & 0.620 & 1.081 \\
\hline Daughter/son-in-law & 0.128 & 0.598 \\
\hline Mother/father & 0.454 & 0.821 \\
\hline Sister/brother & 0.860 & 1.047 \\
\hline Other & 0.425 & 1.219 \\
\hline Occupational status of primary carer (ref: employed) & 0.000 & \\
\hline Unemployed & 0.000 & 0.451 \\
\hline Household tasks & 0.000 & 0.507 \\
\hline Other & 0.002 & 0.641 \\
\hline Level of education of carer(ref: primary or less) & 0.196 & 0.856 \\
\hline Co-residence (ref: Yes) & 0.023 & 1.651 \\
\hline Daily hours of care received (ref: 0-2.99) & 0.001 & \\
\hline $3-8.99$ & 0.001 & 1.596 \\
\hline $9+$ & 0.000 & 1.667 \\
\hline Time primary carer providing care (0-1.99 years) & 0.203 & \\
\hline $2-7.99$ & 0.470 & 0.902 \\
\hline $8+$ & 0.552 & 1.087 \\
\hline Carer problems due to care (ref: no) & 0.000 & 2.561 \\
\hline Constant & 0.001 & 0.227 \\
\hline
\end{tabular}

$\mathrm{N}: 2.896$ Chi-square: $279.526 p<0.001$. Nagelkerke's $R^{2}: 0.149$.

Note 1: Multicollinearity tests: lowest tolerance factor $=0.611$; highest VIF $=1.636$.

Source: 2008 Spanish Survey on Disability, Personal Autonomy and Dependency Situations. 
In the unmet needs model for those who receive only paid care (Table 5), the variable 'place of residence of primary carer' demonstrates predictive capacity for the perception of unmet needs: having a carer who does not live with the dependent person makes the dependent more likely to consider his/her needs as unmet $(\mathrm{OR}=4.006)$.

Table 5.

Logistic regression model of perception of unmet needs. People receiving only paid care

\begin{tabular}{|c|c|c|}
\hline Perception of needs (ref: receive all care he/she needs) & P-value & OR \\
\hline Gender (ref: male) & 0.127 & 2.107 \\
\hline Number of disabilities (ref: 1-6) & 0.107 & \\
\hline $7-11$ & 0.066 & 2.379 \\
\hline $12+$ & 0.060 & 2.558 \\
\hline Dependent person's age (ref: 18-64) & 0.193 & \\
\hline $64-79$ & 0.071 & 0.317 \\
\hline $80+$ & 0.213 & 0.458 \\
\hline Level of education of dependent person (ref: primary school or less) & 0.163 & 0.467 \\
\hline Number of household members (ref: 1) & 0.927 & \\
\hline 2 & 0.970 & 0.982 \\
\hline $3+$ & 0.723 & 0.775 \\
\hline Monthly household income (ref: -500 euros) & 0.988 & \\
\hline $500-999$ & 0.951 & 1.033 \\
\hline+1000 & 0.931 & 1.062 \\
\hline No answer & 0.780 & 0.771 \\
\hline Population size (ref: $100,000^{+}$) & 0.710 & \\
\hline $10,001-100,000$ & 0.490 & 0.712 \\
\hline $10,000-$ & 0.478 & 0.719 \\
\hline Co-residence (ref: Yes) & 0.049 & 4.006 \\
\hline Level of education of carer(ref: primary or less) & 0.532 & 1.286 \\
\hline Daily hours of care received (ref: 0-2.99) & 0.187 & \\
\hline $3-8.99$ & 0.314 & 1.621 \\
\hline $9+$ & 0.413 & 0.566 \\
\hline Time primary carer providing care (0-1.99 years) & 0.766 & \\
\hline $2-7.99$ & 0.611 & 1.263 \\
\hline $8+$ & 0.540 & 1.635 \\
\hline Nationality of primary carer (ref: Spanish) & 0.890 & 1.076 \\
\hline Constant & 0.037 & 0.083 \\
\hline
\end{tabular}

$\mathrm{N}: 221$. Chi-square: $37.814 \mathrm{p}=0.009$.Nagelkerke's $\mathrm{R}^{2}: 0.235$.

Note 1: Multicollinearity tests: lowest tolerance factor $=0.348$; highest $\mathrm{VIF}=2.876$.

Note 2: Statistical significance must be interpreted with caution due to the number of cases and categories included in the model.

Source: 2008 Spanish Survey on Disability, Personal Autonomy and Dependency Situations. 
Table 6 shows the unmet needs model for those who only receive care from social services. The only significant variable is the severity of the disability: needing help in 12 or more ADLs as compared to needing help in six or less increases the probability that the social services alone do not adequately cover the dependent person's care needs $(\mathrm{OR}=12.992)$.

Table 6.

Logistic regression model of perception of unmet needs. People receiving only public care

\begin{tabular}{lcc}
\hline Perception of needs (ref: receive all care he/she needs) & P-value & OR \\
\hline Gender (ref: male) & 0.376 & 0.606 \\
Number of disabilities (ref: 1-6) & 0.000 & \\
$7-11$ & 0.960 & 1.022 \\
$12+$ & 0.000 & 12.992 \\
Dependent person's age (ref: 18-64) & 0.233 & \\
$64-79$ & 0.092 & 4.096 \\
$80+$ & 0.114 & 3.637 \\
Level of education of dependent person (ref: primary school or less) & 0.056 & 0.263 \\
Number of household members (ref: 1 ) & 0.946 & 1.041 \\
Monthly household income (ref: -500 euros) & 0.593 & \\
$500-999$ & 0.338 & 0.651 \\
+1000 & 0.189 & 0.322 \\
No answer & 0.655 & 0.559 \\
Population size (ref: 100,000+) & 0.587 & \\
$10,001-100,000$ & 0.382 & 1.598 \\
10,000- & 0.410 & 1.460 \\
Daily hours of care received (continuous variable) & 0.210 & 0.785 \\
Constant & 0.385 & 0.442 \\
\hline N 137. Chisqua
\end{tabular}

$\mathrm{N}: 137$. Chi-square $35.079 \mathrm{p}=0.003$. Nagelkerke's $R^{2}: 0.289$.

Note 1: Multicollinearity tests: lowest tolerance factor $=0.547$; highest $\mathrm{VIF}=1.828$.

Note 2: Statistical significance must be interpreted with caution due to the number of cases and categories included in the model.

Source: 2008 Spanish Survey on Disability, Personal Autonomy and Dependency Situations. 


\section{Discussion}

The majority of prior studies about needs satisfaction of dependent individuals in Spain and elsewhere have not explored the influence of the type of care provided. Therefore, there is a lack of information about how different sources of care are related to the perception of unmet needs of the care recipients. This article considers different combinations of sources of care and other relevant factors, and explores their differential influence on the perception of unmet needs.

According to our results, $29.4 \%$ of dependent Spanish people over 17 years of age do not perceive that their care needs are adequately covered. In Spain, Tomás Aznar et al. (2002) found that the prevalence of unmet needs in personal care of non-institutionalised dependent people over 74 years of age in a specific area in Zaragoza was $22.1 \%$. Otero et al. (2003) found that $40 \%$ of older people in Leganés had unmet needs in some IADLs. Rogero-García and Ahmed-Mohamed (2011) estimated that $29 \%$ of dependents over the age of 59 who received care perceived their needs as unmet. In terms of other countries, previous studies of older individuals living in the United States have estimated that amongst those living in the community, between $2 \%$ and $35 \%$ of the dependents (depending on what is included in the definition of needs) does not perceive their needs as being covered (Williams, Lyons and Rowland 1997).

The first objective of this paper was to identify the combination of care that achieves the lowest perception of unmet needs. Our general model shows that the source of care is significantly related to unmet needs perception. Thus, our first hypothesis is confirmed. Nevertheless, hypotheses related to the role of the different sources of care are only partially confirmed. Contrary to our second and fourth hypotheses, our results show that dependents who receive care exclusively from family or friends are not the group that is most likely to perceive their needs as having been met. Firstly, a plausible explanation may be that theoretical preferences of the general population (measured by IOÉ and Rodríguez (1995) and IMSERSO (2005)) are not the same as dependent people's satisfaction in terms of met needs, as measured in our analysis. It is reasonable to think that people without actual care needs have a different view of personal support than those who are actually in need of care. Secondly, there are changing trends towards smaller families (the result of a desire for greater privacy among adult children and increased participation of women in the labour market) that are altering the family's traditional capability and motivation to provide care ( $\mathrm{Ng}$ 2007). Third, dependents' physical and psychological needs are complex, and sometimes the family bond is not the most suitable way of covering them (Riess-Sherwood, Given and Given 2002). Another qualitative study (Fundación Cirem 2004) suggested this idea, highlighting negative effects on the dependent's satisfaction with the care they received due to the emotional bond with their family.

A relevant and original result of our work is that people in Spain who receive only paid care are most likely to perceive their needs as having been met. This result reveals that when compared to other sources of care, private care includes aspects which are important for dependent adults. It suggests that dependent people are less likely to perceive 
unmet needs with professional care, where the activities to be performed and the salary are clearer than in family care. Along these lines, Galvin (2004), using qualitative data from New Zealand, Australia, the United Kingdom and the United States, found that people who received paid care felt more comfortable with the relationship with their carer and had greater control of their lives. On the other hand, people who received informal care often felt embarrassed and had a constant need to show their gratitude for the care received. The importance of feeling like a burden has been reflected in the study by Matthias and Benjamin (2008), which explored the satisfaction of people cared for by different carers and their relationship with these carers. However, this does not mean that informal care is an ineffective type of care, as the dependents perceive it more positively than any other type or combination of care, with the exception being in the case of receiving solely paid care. What these figures appear to suggest is that dependent adults rate paid care very positively. This source of care is as intensive as family care and does not give rise to the implications involved in the case of an emotional bond. This positive view of paid care was also found by Rogero-García and Ahmed-Mohamed (2011) for Spanish people over the age of 59.

According to our third hypothesis, we found that social services, either supplied alone or together with other care providers (family/friends or paid care), are the least effective source of care, based on their probability of producing a low perception of needs' satisfaction. This suggests that these services are perceived by the users as inefficient in terms of needs being met. This may be due to the fact that they do not provide all the care-related tasks and therefore do not cover all needs, or that they carry out these tasks on an ad hoc basis. The limited importance of public formal care in comparison with informal and paid care has also been found for the United Kingdom (Vlachantoni et al. 2011). This indicates that public services are perceived as insufficient (Daatland 1997). Our findings also show that people being cared for by a combination of care providers are less likely to perceive their needs as being covered. Accordingly, a previous study by Hardy, Young and Wistow (2001) in four local authority areas in England revealed that an increase in the number of services received does not necessarily mean that they have been selected by the dependent person.

The second goal of this paper was to identify factors influencing the perception of needs as unmet for each source of care. Factors related to the context, dependent person, primary carer, and the care itself were analysed. The results show that these four types of variables accounted for the probability of perceiving needs as unmet. Women had a higher probability of perceiving unmet needs when they received only informal care and not when they received only paid or public care. Similar results were found in Spain by Tomás Aznar et al. (2000), although without controlling for the number of household members, by González and Urbanos (2004) for medical and care services amongst people under 65 years of age, and by Allen and Mor (1997) in the United States. In the majority of the studies, it was pointed out that there is no evidence indicating that the dependent person's gender is related to satisfaction with health care (Sitzia and Wood 1997). Along these lines, Otero et al. (2003) did not find 
a significant relationship between gender and unmet needs, and Bauld, Chesterman and Judge (2000) indicated that women usually report higher levels of satisfaction with community care services than men.

As with previous research, unmet needs showed a positive correlation with a person's disability level (Allen and Mor 1997; Desai, Lentzner and Weeks 2001, Geron et al. 2000). This is supported by the fact that people who experience pain and anxiety perceive less satisfaction with care (Bauld, Chesterman and Judge 2000). In line with our results on age, Allen and Mor (1997) found that unmet needs were higher amongst older adults under 65 years of age. They suggested that this is because this age group had fewer economic resources than people over 64 years of age, who had savings and other economic resources to meet expenses arising from dependence situations. As explained by Sitzia and Wood (1997), it has often been argued that satisfaction with care is lower amongst younger adults because their expectations are higher. Older people's expectations are lower because they are not used to current standards of public protection and are more likely to be satisfied than younger people (Bauld, Chesterman and Judge 2000).

We did not find a statistically significant relationship between level of education and unmet needs perception. Studies carried out in this area offer contradictory results (Sitzia and Wood 1997). Hall and Dornan (1990) suggested that in the United States there is greater dissatisfaction with medical care amongst those with a higher level of education. Another study conducted in the same country with people who were 70 years of age or older found that unmet care needs increased in those with a lower level of education (Desai, Lentzner and Weeks 2001). In Spain, Otero et al. (2003) did not discover any relationship between the level of education and unmet care needs.

According to our results, people living alone are more likely to perceive unmet needs than those that live in households with three or more people. Previous studies have shown that people living alone are more likely to have unmet needs (Desai, Lentzner and Weeks 2001; Tomás Aznar et al. 2002; Williams, Lyons and Rowland 1997). These results indicate that the care network is a key factor in the well-being of dependent people. Along these lines, Allen and Mor (1997) found that unmet needs rose as the number of people who the dependent person could count on decreased. Additionally, dissatisfaction with care is higher amongst unmarried people (Williams, Lyons and Rowland 1997).

Our findings are in line with the idea that, amongst people receiving only informal care, higher household incomes contribute to a better coverage of needs. Household income is not a significant variable in paid and public care models, probably because these groups are more homogeneous in terms of economic resources. Desai, Lentzner and Weeks (2001) and Otero et al. (2003) found that people with very low incomes are significantly more likely to have unmet care needs. This may be due, amongst other factors, to the positive relationship between economic resources and health status (Williams, Lyons and Rowland 1997) and the relationship between those resources and the availability of additional technical and personal help (Rogero-García and Rosenberg 2011). However, according to Bauld, Chesterman and Judge (2000), there is no evidence that social class affects responses of dependent people regarding their satisfaction with care. 
We have found that people living in large cities are more likely to identify unmet needs if they only receive informal care. In Spain, this may be, in part, because people living in large cities have a lower degree of informal support than those who live in places with small and medium-sized populations (Rogero-García and Rosenberg 2011). The results also suggest that perception of needs coverage is higher when the informal carer is a woman. Women often carry out this type of work in the home and can therefore be seen as being specialised in completing care tasks. This specialisation has been explained by the remaining elements of the traditional socialisation of women (Walker and Pratt 1991).

When an informal carer spends more than three hours per day providing care, there is an increased probability that the dependent person will not perceive his/her needs as having been met. The family carer's well-being depends on the well-being of the person he/she is caring for (Bauld, Chesterman and Judge 2000), so any improvement in the well-being of either one will have a positive impact on the other and vice versa (Brouwer et al. 1999). This relationship is confirmed here by the fact that, in cases where the family carer has a problem related to the care situation, as compared to cases where there are no problems, it is far more likely that the dependent person will be unsatisfied with the care received. In problematic cases, the care receiver may perceive a reduction in the carer's quality of life and the principle of reciprocity is broken, resulting in dissatisfaction with the situation. In this respect, Matthias and Benjamin (2008) found that those who receive informal care are more likely than those who receive formal care to consider themselves to be a burden and become depressed.

The forms of cohabitation of dependent people are crucial to satisfying their care needs (Ahmed et al. 2009). Living together in the same residence as the primary carer is related to increased needs satisfaction, both in those who receive only informal care and those who receive only paid care. Carers who live with the dependent person spend more time caring for them (Bittman et al. 2004) and perform a wider variety of tasks (Fast et al. 2004). Moreover, cohabitation improves the relationship between the carer and care receiver (Call et al. 1995; Dwyer, Le and Jankowski 1994) and is associated with lower levels of depression amongst carers (Montoro 1999), although not every aspect of cohabitation that was analysed had a positive effect (Dwyer, Le and Jankowski 1994; Walker, Pratt and Eddy 1995).

It is notable that the logistic regression model amongst those who only receive informal care does not show a significant relationship between perception of needs coverage and the type of relationship between the carer and care receiver. The family appears to be just as effective at providing care, irrespective of the individual family member who actually provides the care. There is no evidence therefore of the hierarchical-compensatory model, which suggests that dependent adults prefer to be cared for first by their spouse, followed by their children, other members of the family and, finally, formal carers (Cantor 1979).

The work presented here has limitations which must be considered when interpreting its results. First, the selected sample only includes those cases in which the dependent person responded directly (proxies are not included). The sample is therefore not repre- 
sentative in terms of the severity of the disability because people who could not directly respond to the survey were not represented in the analysis. Second, we should note that the dependent variable (felt and expressed needs) is not equivalent to 'real needs' (Bradshaw 1974). Expressed needs may reflect real needs, but could also contain additional elements related to wants and desires. In this sense, the data source used does not incorporate the professional assessment of the dependent adults' needs and does not capture their perception of different aspects of care (McWalter et al. 1994). These elements would have increased the validity of our results. Third, studies on satisfaction with the care received may also be affected by a number of biases (Sitzia and Wood 1997). On the one hand, some interviews may be held in the presence of carers, with resulting limitations on the ability to respond openly and freely. On the other hand, a bias may be due to reasons relating to self-interest. For example, people may believe that if they express satisfaction with their care, they may be more likely to receive this level of care in the future (Bauld, Chesterman and Judge 2000). Or vice versa, they may think that if they question the care they receive, this care may improve in the future. For future work, it would be advisable to complement these findings with qualitative data, as open interviews would allow the interviewee to explain the background and context and could prevent the misinterpretation of their responses (Gilbert, Lankshear and Petersen 2007).

\section{Conclusions}

Irrespective of its limitations, this work provides new and consistent findings on the care of dependent adults. The results show that a significant percentage of this population believes that they have unmet care needs. According to our results, the current structure of care provision in Spain does not appear to be the most appropriate. Although the Spanish care model mainly focuses on family care, the analyses reveal that this type of care, although preferable to others, is not perceived as the one most likely to meet the needs of dependent adults. Therefore, the results question the utility of promoting the family as the most appropriate care provider. The care provided by paid carers appears to be the best in terms of perception of needs having been met. Further research is needed to examine if beneath these perceptions there lies a weakening of the traditional associations between formal care and technical specialisation and informal care and inter-personal bonds (Donabedian 1988).

This study also shows that the public sector plays a limited role in responding to care needs, as it is less likely that the dependents will perceive that social services meet their needs. Unpaid and paid care by the family is usually provided for more hours than social services in Spain. In other countries like Canada, the difference in the amount of care received from the family or the private sector versus the public sector is considerably smaller, and, consequently, the coverage of needs achieved by the public services is significantly higher (Dubuc et al. 2011). Taking into consideration the weak socioeconomic position of many Spanish dependent adults, the social protection policies for this group 
should improve the available public services and increase access by these individuals to the formal care market. In this respect, legal measures that entitle dependent people to economic benefits allowing them to hire qualified carers could have positive outcomes.

\section{REFERENCES}

Ahmed, K., Rojo, F., Fernández-Mayoralas, G., Prieto, M. E., Rodríguez, V. and Lardiés, R. 2009. "Red familiar y distancia afectiva en la calidad de vida de la población mayor." Pp. 375-385 in L. López Trigal and A. Abellán García (eds) Despoblación, envejecimiento y territorio: un análisis sobre la población española. León: Universidad de León.

Allen, S. M. and Mor, V. 1997. "The Prevalence and Consequences of Unmet Need Contrasts Between Older and Younger Adults with Disability." Medical Care 35(11): 1132-1148.

Anttonen, A. and Sipilä, J. 1996. "European Social Care Services: Is it Possible to Identify Models?" Journal of European Social Policy 6(2): 87-100.

Asadi-Lari M., Tamburini, M. and Gray, D. 2004. "Patients' Needs, Satisfaction, and Health Related Quality of Life: Towards a Comprehensive Model." Health and Quality of Life Outcomes 2: 32.

Bauld, L., Chesterman, J. and Judge, K. 2000. "Measuring Satisfaction with Social Care amongst Older Service Users: Issues from the Literature." Health and Social Care in the Community 8(5): 316-324.

Bettio, F. and Plantenga, J. 2004. "Comparing care regimes in Europe." Feminist Economics 10(1): 85-113.

Billings, J. R. and Cowley, S. 1995. "Approaches to Community Needs Assessment: A Literature Review." Journal of Advanced Nursing 22: 721-730.

Bittman, M., Fast, J., Fisher, K. and Thomson, C. 2004. "Making the Invisible Visible: The Life and Time(s) of Informal Caregivers." Pp. 69-89 in N. Folbre and M. Bittman (eds) Family Time: The Social Organisation of Care. London and New York: Routledge.

Bradshaw, J. 1974. "The Concept of Social Need." Ekistics 37: 184-187.

Brouwer, W., Van Exel, N. J. A., Koopmanschap, M. A. and Rutten, F. F. H. 1999. "The Valuation of Informal Care in Economic Appraisal. A Consideration of Individual Choice and Societal Costs of Time." International Journal of Technology Assessment in Health Care 15(1): 147-160.

Call, K. T., Finch, M.A., Huck, S. M. and Kane, R. A. 1999. "Caregiver Burden from a Social Exchange Perspective: Caring for Older People after Hospital Discharge." Journal of Marriage and the Family 61(3): 688-699.

Cantor, M. 1979. "Neighbors and Friends." Research on Aging 1: 434-463.

Carretero, S., Garcés, J., Ródenas, F. and Sanjosé, V. 2009. "The Informal Caregiver's Burden of Dependent People: Theory and Empirical Review." Archives of Gerontology and Geriatrics 49: 74-79.

Casado-Marín, D. 2006. "La atención a la dependencia en España." Gaceta Sanitaria 20: 135-142. 
Cowley, S., Bergen, A., Young, A. and Kavanagh, A. 2000. "A Taxonomy of Needs Assessment, Elicited from a Multiple Case Study of Community Nursing Education and Practice." Journal of Advanced Nursing 31(1): 126-134.

Crow, R., Gage, H. and Hampsom, S. 2002. "The measurement of satisfaction with healthcare: implication for practice from a systematic review of the literature." Health Technology Assessment 6: 1-244.

Daatland, S. O. 1997. "Welfare Policies for Older People in Transition? Emerging Trends and Comparative Perspectives." Scandinavian Journal of Social Welfare 6: 153-161.

Desai, M. M., Lentzner, H. R., Weeks, J. D. 2001. "Unmet Need for Personal Assistance with Activities of Daily Living Among Older Adults." The Gerontologist 41(1): 82-88.

Donabedian, A. 1988. "The Quality of Care: How Can it be Addressed?" Journal of the American Medical Association 260: 1743-1748.

Dubuc, N., Dubois, M. F., Raîche, M., Gueye, N. D. R. and Hébert, R. 2011. "Meeting the Home-Care Needs of Disabled Older Persons Living in the Community: Does Integrated Services Delivery Make a Difference?" BMC Geriatrics 11(1): 67.

Dwyer, J. W., Le, G. R. and Jankowski, T. B. 1994. "Reciprocity, Elder Satisfaction, and Caregiver Stress and Burden: The Exchange of Aid in the Family Caregiving Relationship." Journal of Marriage and the Family 56(1): 35-43.

Escuredo, B. 2007. "Las políticas sociales de dependencia en España: contribuciones y consecuencias para los ancianos y sus cuidadores informales." Revista Española de Investigaciones Sociológicas 119: 65-90.

Esping-Andersen, G. 1999. Social Foundations of Postindustrial Economies. Oxford: Oxford University Press.

European Commission. 2009. 2009 Ageing Report: Economic and Budgetary Projections for the EU-27 Member States (2008-2060). Brussels: European Commission.

Fast, J., Keating, N., Otfinowski, P. and Derksen, L. 2004. "Characteristic of Family/Friend Care Networks of Frail Seniors." Canadian Journal on Aging 23(1): 5-19.

Fundación CIREM. 2004. Imagen social y laboral de las personas con discapacidad en España. Madrid: Ministerio de Trabajo y Asuntos Sociales.

Galvin, R. 2004. "Challenging the Need for Gratitude: Comparisons Between Paid and Unpaid Care for Disabled People." Journal of Sociology 40(2): 137-55.

Geron, S. M., Smith, K., Tennstedt, S., Jette, A., Chassler, D. and Kasten, L. 2000. "The Home Care Satisfaction Measure: A Client-Centered Approach to Assessing the Satisfaction of Frail Older Adults with Home Care Services." Journal of Gerontology: Social Sciences 55B(5): S259-S270.

Gilbert, A., Lankshear, G. and Petersen, A. 2007. "Older Family-Carers' Views on the Future Accommodation Needs of Relatives who have an Intellectual Disability." International Journal of Social Welfare 17: 54-64.

González, B. and Urbanos, R. M. 2004. "Oferta pública y privada de servicios sanitarios por comunidades autónomas." Gaceta Sanitaria 18(1): 82-89.

Hardy, B., Young, R. and Wistow, G. 2001. "Dimensions of Choice in the Assessment and Care Management Process: The Views of Older People, Carers and Care Managers." Health and Social Care in the Community 7(6): 483-491. 
Harlton, S-V., Fast, J. and Keating, N. 1998. "Defining Eldercare for Policy and Practice: Perspectives Matter." Family Relations 47(3): 281-288.

Harrel, F. E. 2001. Regression Modeling Strategies with Applications to Linear Models Logistic Regression and Survival Analysis. New York: Springer.

Hosmer, D. and Lemeshow, S.1989. Applied Logistic Regression. New York: John Wiley \& Sons.

IMSERSO. 2005. Cuidados a las personas mayores en los hogares españoles. El entorno familiar. Madrid: IMSERSO.

IMSERSO-CSIC. 2012. Estadísticas del sistema para la autonomía y la atención a la dependencia. Situación a 1 de enero de 2012. Madrid: IMSERSO-CSIC.

INE. 2008. Encuesta de Discapacidad, Autonomía personal y situaciones de Dependencia 2008. Metodología. Madrid: National Statistics Institute.

IOÉ, C. and Rodríguez, P. 1995. Cuidados en la vejez. El apoyo informal. Madrid: INSERSO.

Isaacs, B. and Neville, Y. 1976. "The Needs of Older People.The 'Interval' as a Method of Measurement." British Journal of Preventive \& Social Medicine 30: 79-85.

Jiménez-Martín, S. and Vilaplana, C. 2010. "A Double Simple Selection Model for Unmet Needs, Formal Care and Informal Caregiving Hours of Dependent People in Spain." FEDEA Working Papers 2010-25.

Lai, D. W. L. 2004. "Impact of Culture on Depressive Symptoms of Elderly Chinese Immigrants." The Canadian Journal of Psychiatry 49(12): 820-827.

Langa, D. and Martínez, D. 2009. Redes familiares, cuidados y clases sociales en Andalucía. Madrid: Alianza.

Larizgoitia, A. 2004. Eurofamcare.National Background Report for Spain. Hamburg: Eurofamcare.

Lewinter, M. 1999. Spreading the burden of gratitude: elderly between family and state. Doctoral dissertation, Sociological Institute, Copenhagen.

Lightfoot, J. 1995. "Identifying Needs and Setting Priorities: Issues of Theory, Policy and Practice." Health \& Social Care in the Community 3: 105-114.

Matthias, R. E., Benjamin, A. E. 2008. "Paying Friends, Family Members, or Strangers to Be HomeBased Personal Assistants." Journal of Disability Policy Studies 18(4): 205-218.

McWalter, G., Toner, H., Corser, A., Eastwood, J., Marshall, M. and Turvey, T. 1994. "Needs and Needs Assessment: Their Components and Definitions with Reference to Dementia." Health \& Social Care in the Community 2: 213-219.

Mestheneos, E. and Triantafillou, J. 2005. Supporting Family Carers of Older People in Europe - the Pan-European Background. Hamburg: Eurofamcare.

Montgomery, R. J. V. 1999. "The Family Role in the Context of Long-Term Care." Journal of Aging and Health 11(3): 383-416

Montoro, J. 1999. "Las consecuencias psicosociales del cuidado informal a personas mayores." Revista Internacional de Sociología 23: 7-29.

Norusis, M. 2005. SPSS 13.0. Advanced Statistical Procedures Companion. New Jersey: Prentice Hall. 
Ng, G. T. 2007. "Learning from Japanese Experience in Aged Care Policy." Asian Social Work and Policy Review 1(1): 36-51.

Otero, A., García de Yebenes, M., Rodriguez-Laso, A. and Zunzunegui, M. V. 2003. "Unmet Home Care Needs among Community-Dwelling Elderly People in Spain." Aging Clinical and Experimental Research 15(3): 234-242.

Pérez, A., Paiewonsky, D. and García Domínguez, M. 2008. Cruzando Fronteras II. Migración y desarrollo desde una perspectiva de género. Madrid: Instituto de la Mujer/UN-INSTRAW.

Pommer, E., Woittiez, I. and Stevens, J. 2007. Comparing Care. The Care of the Elderly in Ten EU-countries. The Hague: The Netherlands Institute for Social Research/SCP.

Quail, J., Addona, V., Wolfson, C., Podoba, J., Lévesque, L. and Dupuis, J. 2007. "Association of Unmet Need with Self-Rated Health in a Community Dwelling Cohort of Disabled Seniors 75 Years of Age and Over." European Journal of Ageing 4(1): 45-55.

Riess-Sherwood, P., Given, B. A. and Given, Ch.W. 2002. "Who Cares for the Caregiver: Strategies to Provide Support." Home Health Care Management and Practice 14(2): 110-21.

Rodríguez, V. (ed.) 2012. Inmigración y cuidados de mayores en la Comunidad de Madrid. Madrid: Fundación BBVA.

Rogero-García J. 2011. "El cuidado a las personas dependientes por discapacidad en España y el papel de las familias, a examen." Pp.79-96 in D. Casado (ed) Acción y políticas de apoyo a las familias. Crianza, atención a la dependencia y renovación demográfica. Barcelona: Hacer Editorial.

Rogero-García J. and Rosenberg M. W. 2011. "Paid and unpaid support received by co-resident informal caregivers attending to community-dwelling older adults in Spain." European Journal of Ageing 8(2): 95-107.

Rogero-García, J. and Ahmed-Mohamed, K. 2011. "Satisfaction of Needs of Disabled People 60 and over According to Care Provider. Spain, 2008." Revista Española de Salud Pública 85(6): 541-553.

Sitzia, J. and Wood, N. 1997. "Patient Satisfaction: A Review of Issues and Concepts." Social Science and Medicine 45(12): 1829-1843.

Spanish Law 39/2006. 2006. Official State Gazette (BOE).

Sprangers, M. A. G. and Aaronson, N. K. 1992. "The Role of Health Care Providers and Significant Others in Evaluating the Quality of Life of Patients with Chronic Disease: A Review." Journal of Clinical Epidemiology 45(7): 743-760.

Thorslund, M., Bergmark, A. and Parker, M. G. 1997. "Difficult Decisions on Care and Services for Elderly People: The Dilemma of Setting Priorities in the Welfare State." Scandinavian Journal of Social Welfare 6: 197-206.

Todorov, A. and Kirchner, C. 2000. "Bias in Proxies' Reports of Disability Data from the National Health Interview Survey on Disability." American Journal of Public Health 90(8): 1248-1253.

Tomás Aznar, C., Moreno Aznar, L., Germán Bes, C., Alcalá Nalváiz, T. and Andrés Esteban, E. 2002. "Dependencia y necesidades de cuidados no cubiertas de las personas mayores de una zona de salud de Zaragoza." Revista Española de Salud Pública 76(3): 215-226.

Vlachantoni, A., Shaw, R., Willis, R., Evandrou, M., Falkingham, J. and Luff, R. 2011. Measuring Unmet Need for Social Care among Older People. Population Trends 145: 1-17. Office for National Statistics. 
Walker, A. J. and Pratt, C. C. 1991. "Daughters' Help to Mothers: Intergenerational Aid versus Caregiving." Journal of Marriage and the Family 53(1): 3-12.

Walker, A. J., Pratt, C. C. and Eddy, L. 1995. "Informal Caregiving to Ageing Family Members: A Critical Review." Family Relations 44(4): 402-411.

Willard, L. D. 1982. "Needs and Medicine." Journal of Medicine \& Philosophy 7(3): 259-274.

Williams, J., Lyons, B. and Rowland, D. 1997. "Unmet Long-Term Care Needs of Elderly People in the Community: A Review of the Literature." Home Health Care Services Quarterly 16(1): 93-119.

Jesús Rogero-García holds a PhD in Sociology at Universidad Complutense de Madrid. His research focuses on adult care, childcare and education. He is currently a Lecturer in the Department of Sociology at Universidad Autónoma de Madrid.

Karim Ahmed-Mohamed is PhD in Social Work and holds degrees in Political Science, Social Work, Social Anthropology, and Sociology. He is currently an adjunct professor at Sociología IV Department in Complutense University. He has published in indexed journals as Journal of Social Work Practice, Ageing \& Society or International Social Work. His main research interests are social research methods, ageing, citizen participation and community social work.

RECIBIDO: $12 / 09 / 2012$

ACEPTADO: 25/06/2013

Publicado on-line: 02/04/2014 